\title{
DRIVER'S REACTION TIME IN A SIMULATED, COMPLEX ROAD INCIDENT
}

\author{
Rafał Stanisław Jurecki, Tomasz Lech Stańczyk, Marek Jacek Jaśkiewicz \\ Faculty of Mechatronics and Machine Design, Kielce University of Technology, Poland \\ Submitted 17 May 2013; accepted 20 August 2013; \\ first published online 9 May 2014
}

\begin{abstract}
This paper presents an overview of research on the behaviour of drivers in simulated accident situations. The research was carried out by the authors of this work as a part of a research N N509 549040 funded by the National Science Centre including new accident situations. The paper presents a description of the methodology and implementation of research on a track. During the tests, the simulation concerns about an accident risk situation involving pedestrians and passenger cars intruding the road area. In contrast to earlier research carried out by the authors, the scenario included the possibility of a pedestrian 'entering' from behind a curtain, both from the left and from the right sides of the road. This was possible thanks to a specially developed test stand. The paper analyses the values of driver's reaction times characteristic to driver's impact on: acceleration control pedals, service brake and steering wheel. In addition to the determination of average reaction time values and the regression line for the test group of 30 drivers, the assessment of the frequency of drivers taking individual defensive reactions was carried out.
\end{abstract}

Keywords: traffic safety; collision; road accidents; regression equation; simulation.

\section{Introduction}

Currently, reconstruction and analysis of traffic accidents are carried out using sophisticated computerized systems for traffic simulation and reconstruction of their movement. Most of them can generate a computer animation of a reconstructed accident situation, so that it can be presented in a film form. Such presentation of reconstruction results has some advantages. Therefore, the reconstruction result is presented not as complicated calculations which are not understandable to people outside the industry, but as a film, in other words, as a scene, where background environment can be a real scene of an accident.

Unfortunately, we need to realize that this simulation can be very suggestive and influence the feelings of recipients (including the court), and possibly even with committed errors, can have a very significant impact on the outcome of the proceedings. The end result of judicial proceedings concerning the accident depends on how a road accident reconstruction will be carried out, including determining the scope of the guilt and penalty values of individual participants of the analysed road accident. The credibility of the reconstruction carried out by an expert depends on many factors.
A very important factor is the correct choice of input parameters, which during simulation preparation time is used by a court expert by introducing them to the software. A part of the necessary parameters is contained in police documents, many others need to be selected by an expert alone are based on the expert's own experience, and many others are selected based on recommendations from professional literature. These factors include e.g.: the coefficient of surface friction, driver's reaction time, or a restitution coefficient.

According to the values of various parameters adopted for the computer simulation, a fairly large range of uncertainty may occur in a carried out simulation. Applied computational models show a strong sensitivity to the change in the value of a number of parameters used for calculations.

One of the parameters, the value of which can significantly affect the result of a simulation is 'driver's reaction time. This is the time that lasts from the time of accident risk, to the start of driver's influence on the vehicle control mechanisms i.e. steering wheel, pedals and gears.

It is also unrealistic to determine the reaction time for a specific driver as the driver's reaction time can be

Corresponding author: Rafał Stanisław Jurecki

E-mail: rjurecki@tu.kielce.pl 
determined at any given moment by a number of circumstances, for example, Connor et al. (2002).

Available literature contains many test results of drivers' behaviour in emergency situations, including their reaction time. Large variety of testing methodologies and how to analyse the results, involves a large variety of presented reaction times. In view of the diverse types of research, it is difficult to identify the best of the proposed research methods, and thus regards to obtain reaction times, as the only true and validity.

\section{Review of Research Methods Reaction Time of Drivers}

Methodology of driver reaction time is very different. It depends, to a large extent, on the environment in which it is implemented. As they can be conducted on dedicated test stands (for psychological testing), in driving simulators or on test tracks, their method of implementation is significantly different (Green 2000; Hugemann 2002).

Reaction times are determined in studies of driver's reactions to various stimuli. Among the stimuli that act on a driver we may find simple and complex stimuli.

In a study on simple stimuli, the task of a driver is the reaction to one of the elements of the car control e.g.: brake pedal or steering wheel.

An example of research results in which there was the stimulation by such stimuli are studies conducted by Burckhardt et al. (1981). Two vehicles were involved in the experiment carried out by them. A tested driver steering a test passenger car reacted to brake lights illuminated in a car in front. Tests for each of the drivers followed one after another and lasted about one hour.

A similar method was also used in research conducted later in the study by Nishida (1999). In another paper (Fröming 2008) a driver responded to light pulse coming from the unit lights stuck on the windscreen, and on a ring tone placed in a cabin (Törnros 1995).

The values of drivers' reaction times can be affected by a variety of factors related to environment, driver's behaviour and vehicle. These include, for instance, the state of environment, weather, driver's age, driver's emotional state, psycho-motor performance of a driver, presence of alcohol, drugs, medicine and other similar substances in driver's body (Hindmarch 2004; Oxley et al. 2006; Keall et al. 2004; Ogden, Moskowitz 2004; Zöller, Hugemann 1998).

Many studies often conducted in a much simplified way, are implemented to determine the effect of various factors on driver's reaction time. Such factors considered in paper by Consiglio et al. (2003), Alm and Nilsson (1995) is driver's distraction, loss of focus caused by a telephone conversation conducted on a mobile phone (with or without a hands-free set), listening to the radio in a car or talking to a passenger. According to Consiglio et al. (2003), a red test lamp with of $50 \mathrm{~mm}$ diameter was placed at a distance of $2 \mathrm{~m}$ from the eyes of a driver. The experiment measured driver's reaction time between the activation of the red light, the beginning of 'releasing' an accelerator pedal and starts to press a brake pedal.
The above-mentioned test methods have, however, a fundamental defect. These include driver's reaction to a relatively simple stimulus. While analysing accident situations, we should realize that in real road situations, a driver reacts mainly to complex stimuli.

In order to avoid an accident, a driver performs various manoeuvres: braking and bypassing, and the amount of information that he/she is exposed to is also significant. Paper by Magister et al. (2005) describes the study of the reaction to complex stimuli which use light stimulator stuck to the windscreen. This approach has been criticized in many works such as Green (2000), Zöller and Hugemann (1998).

Similar studies were also carried out in a number of projects aimed at building an assistant system to avoid accidents. Such studies used inflatable mock-ups made of thick film - 'balloon' type, characterized by a real shape and dimensions of a vehicle. They could be used to implement two test scenarios referred to as 'violent braking' and 'violent bypass'.

Drivers' behaviour tests carried out at special measuring stands may be connected with reaction time which is determined for disabled drivers or drivers after diseases or surgeries. They may be conducted, among others, to determine the suitability of such persons in road traffic, time of their full recovery, rehabilitation progress, etc. These tests were carried out including persons after orthopaedic surgery such as total replacement of a knee joint (Spalding et al. 1994) or the hip joint (Ganz et al. 2003). The tests also concern the reaction time of drivers (Baulk et al. 2001) in the state of tiredness, sleepiness (Connor et al. 2002), fatigue (Philip et al. 2005) and under the influence of alcohol, for example, Oxley et al. (2006), Zaranka et al. (2011). Many studies are conducted for ill drivers, with the aim to stress the impact of diseases such as Parkinson on drivers' psycho-motor performance (Madeley et al. 1990).

In recent years, a research to some selected specific accident scenarios on roads or test tracks are carried out. An example of such a study could be the one described in paper by McGehee et al. (2000) in which a vehicle intruded the crossroads perpendicularly. Another example can be tests for the reaction to a small children bike (Krause et al. 2007), ball (Dettinger 2008) pushed out (from behind parked cars in the right lane) or a cardboard box (Hillenbrand 2007) thrown onto a lane.

Many studies on the behaviour of drivers in case of emergency situations are also conducted in a virtual environment (for example, Lee et al. 2002). In the study described in paper by McGehee et al. (2000) the behaviour of drivers in both the simulator and on the track were observed. In the simulator, the beginning of an emergency situation was the obstacle of a vehicle picture in 1:1 scale projected on the screen. The track used a foam mock-up of equal dimensions with a photo of a car obstacle.

Number of this type of study, available in literature, is relatively small and it discusses only some special cases.

The studies of the authors conducted in 2004-2005 (Jurecki, Stańczyk 2009, 2011a, 2011b) used a styrofoam 
mock-up entering into the road area when it reaches the proper distance from an obstacle test vehicle (Fig. 1). The study was conducted at a simulated crossroads of two two-lane, two-way roads, with reduced visibility (by the use of double-sided curtains) in both the left and right sides. The behaviour of a driver was recorded using specialized equipment installed in the test vehicle. These studies were also conducted in a driving simulator and

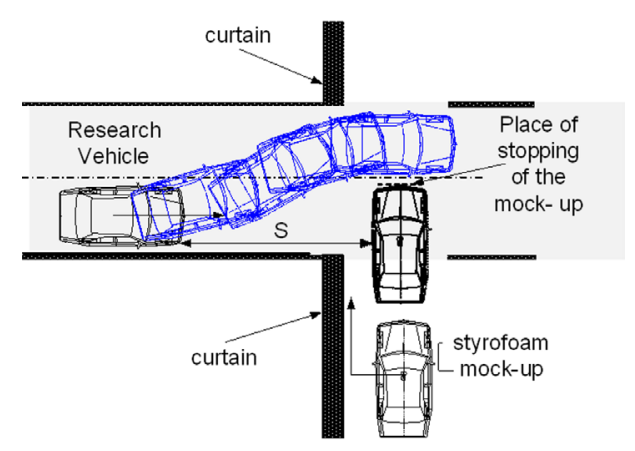

Fig. 1. Diagram of a basic scenario research

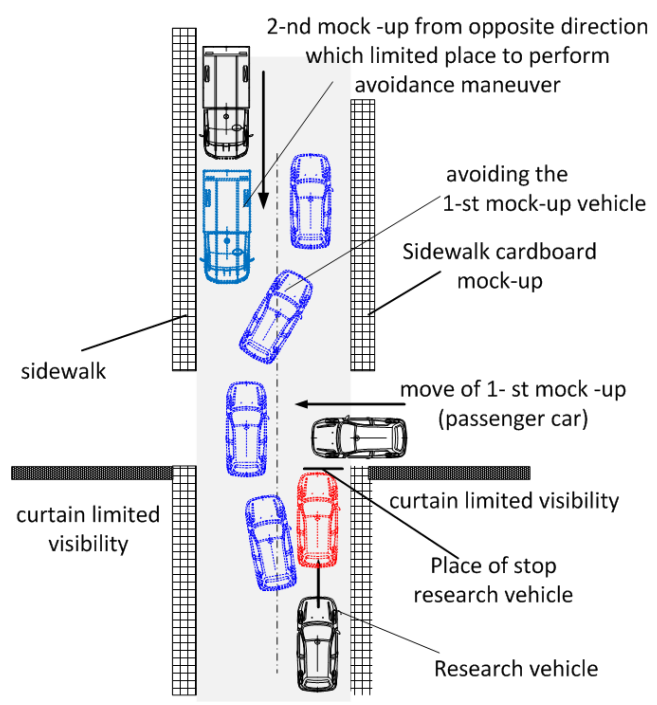

Fig. 2. Diagram of 'Scenario 1'

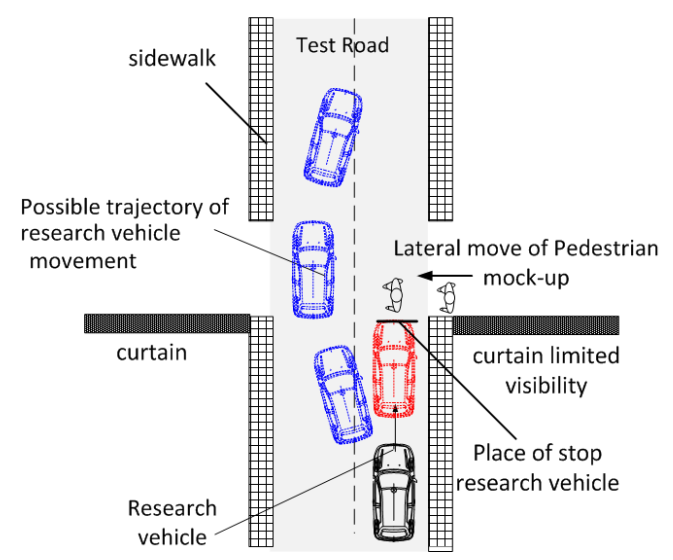

Fig. 3. Diagram of 'Scenario 2' the results have been published in papers by Guzek et al. (2006), Jurecki and Stańczyk (2011a, 2011b).

Other studies carried out by the authors conducted in the years 2006-2010, included three different accident situations. The first of the realized - 'Scenario 1' (Fig. 2), aimed at the simulation of the situation when a passenger car (1-st mock-up) enters perpendicularly on the crossroads from the right side of the road, while from the opposite direction, another vehicle was moving in the direction of the tested car (2-nd mock-up) (Stańczyk et al. 2010).

Next scenario carried out by the authors named 'Scenario 2' was a situation in which the pedestrian entered perpendicularly the road in front of an oncoming vehicle. Pedestrian was moving on the right side of the road on the right lane (Fig. 3) (Stańczyk et al. 2011).

Another realized scenario named 'Scenario 3' mapped a situation where a truck enters in front of an oncoming vehicle from a traverse road from the right side. This vehicle was passing perpendicularly through the crossroads of two-lane roadway. In such a situation both lanes were blocked (it was impossible to bypass it) (Fig. 4) (Stańczyk et al. 2012).

The next implemented 'Scenario 4' used pedestrian mock-ups which entered from the side in the road area, both from the left and right side of the road (Fig. 5).

This is what differed significantly this scenario from previously 'Scenario 2' realized ones.

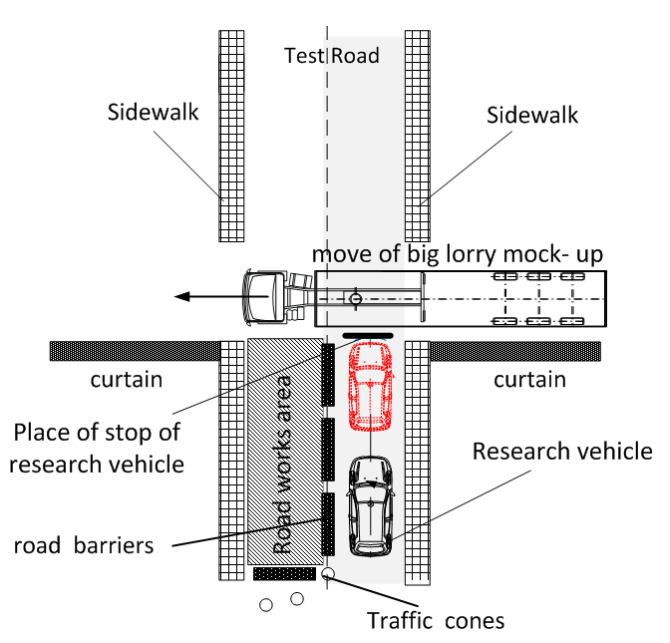

Fig. 4. Diagram of 'Scenario 3'
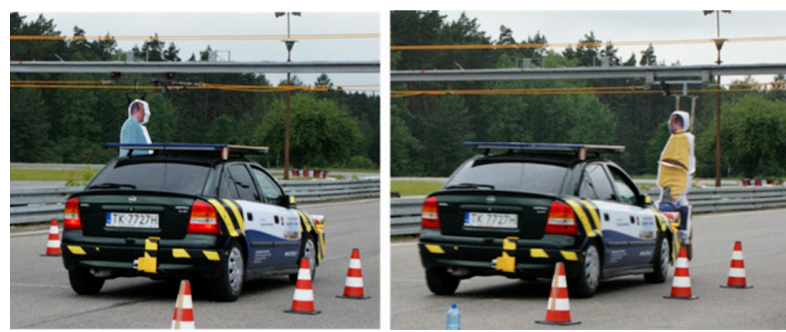

Fig. 5. Photos from the realization of 'Scenario 4' 


\section{Methodology of Research Carried Out on the Test Track}

'Scenario 5' was considered in the studies analysed in this paper. This was the most complex scenario carried out by the authors. Diagram and examples photo of this scenario has been presented in Fig. 6.

Obstacles simulating accident risk were pedestrian mock-ups entering from the left or right sides, and a car mock-up entering across from the right side of the road at the same time.

The authors initiating research into reaction time of drivers in an accident risk, in this scenario, simulated two different accident situations, which will be analysed in the following paper (Fig. 6):

- situation A - a pedestrian mock-up enters the road area from the left side, and a vehicle mockup from the right side;

- situation $B$ - a pedestrian mock-up and a vehicle mock-up entering the road area from the right side;

- the goal of this study was to examine how a seemingly small modification of a scenario (as opposed to 'Scenario 4') - the use of one more additional mock-up (passenger car/vehicle) will affect achieved reaction time results, both in terms of quantity and quality;

- in previously conducted studies on the reaction time for a pedestrian entering from the left or right side, the reaction time for pedestrians entering from the left side were longer. Currently, it was expected that for situation A (a pedestrian from the left side), the differences of time values will be even greater, as in this case, mock-ups entered both lanes. In situation B, left lane was free, so under certain TTC (Time To Collision) values, a driver could, in a more resolute way, choose an avoidance manoeuvre;

- in studies carried out on the track, the way drivers reacted was not imposed on them. The drivers themselves decided about how to apply defensive manoeuvre at a particular moment (only braking, only avoiding obstacles, or both actions at the same time). Each of the 30 tested drivers aged $22 \div 25$, performed 10 rides for both mock-ups entering from the left and from the right sides, for each of TTC values in the range between $0.6 \div 3.0$ s (Table 1 );

- TTC that characterizes an accident situation is the time used in previous studies and publications of the authors (Jurecki, Stańczyk 2009, 2011a, 2011b) when determining in-time distance to an obstacle (in this work sometimes called time risk). TTC is calculated as the quotient of the distance of a vehicle to an obstacle $S$ to its speed $V$ at the time of the accident risk occurrence:

$T T C=\frac{S}{V}$,

where: $S$ - distance from an obstacle; $V$ - vehicle speed from an obstacle.
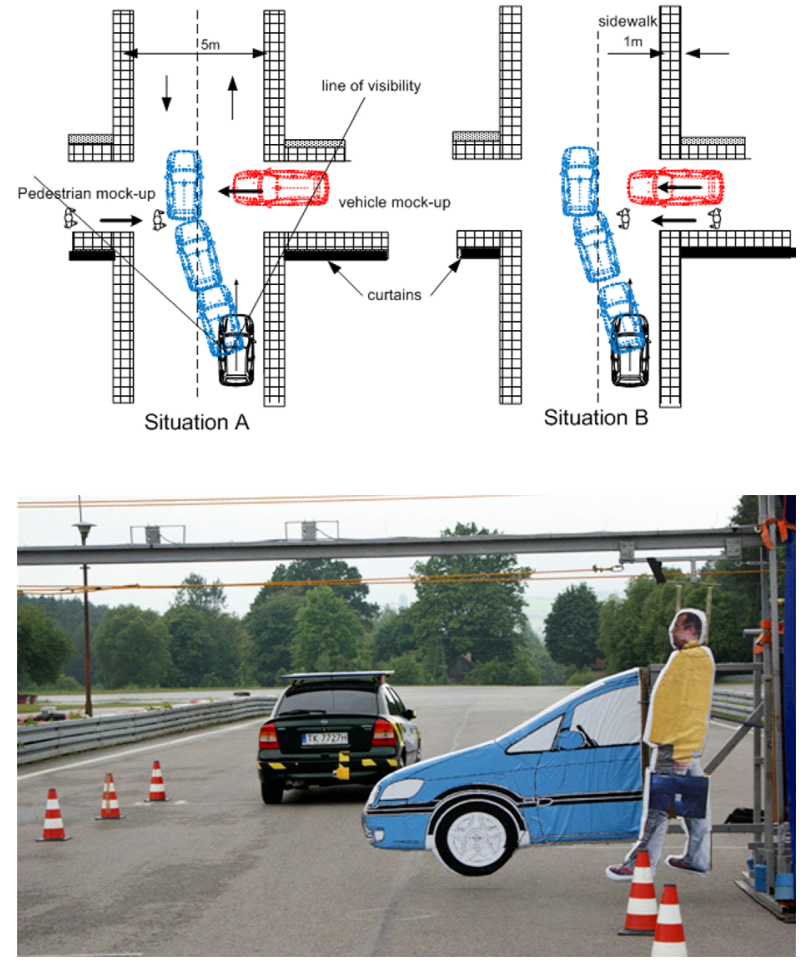

Fig. 6. Diagram of 'Scenario 5' and photo from the analysed scenario

Tests carried out on the track used a specially prepared test vehicle (Fig. 7). The task of a person driving a test vehicle /1/ was to enter into a research section with an appropriate constant vehicle speed $V$ (Table 1).

At the time when a vehicle was positioned level with an active reflector placed on the roadside /2/ (located at the distance $S$ proper for a particular test - see Table 1), caused an activation of a light barrier photocell /3/, which by means of transmitting system /4/ initiated the movement of a left or right pedestrian mock-up /5/, car mock-up movement /6/ and start data acquisition. The change of trigger distance $S$ was carried out by replacing the inactive reflector $/ 7 /$ to an active one $/ 2 /$.

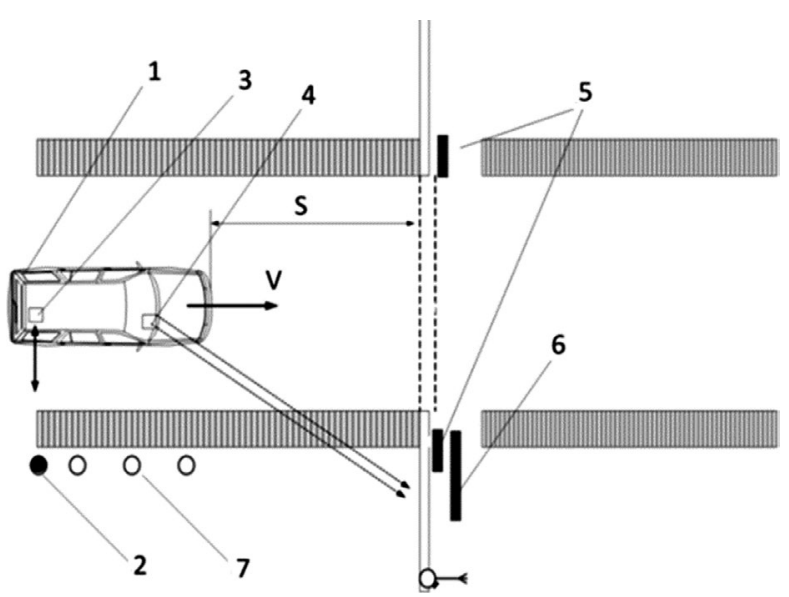

Fig. 7. Diagram of the measurement system on the track 
Table 1. Realised parameters of particular tests

\begin{tabular}{ccccccccccc}
\hline TTC $[\mathrm{s}]$ & 0.60 & 0.72 & 0.90 & 1.20 & 1.44 & 1.80 & 2.16 & 2.40 & 2.70 & 3.00 \\
\hline Speed $V[\mathrm{~km} / \mathrm{h}]$ & 60 & 50 & 40 & 60 & 50 & 40 & 50 & 60 & 40 & 60 \\
\hline Distance $S[\mathrm{~m}]$ & 10 & 10 & 10 & 20 & 20 & 20 & 30 & 40 & 30 & 50 \\
\hline
\end{tabular}

\section{Instrumentation Used to the Study}

Special instrumentation has been used in the current researches. The vehicle Opel Astra G, has undergone some adjustments necessary for the implementation of the research. As it was expected, based on past experience of the authors (Jurecki, Stańczyk 2009), that there will be tests with vehicle and mock-up collisions (some parameters were particularly selected that way) the front (plastic) bumper was demounted. It was replaced by a specially constructed steel piping and front and roof body covers were used. The task of new components was to secure the vehicle from the effects of multiple collisions with mock-ups (Fig. 8). The vehicle was also equipped with suitable measuring equipment.

During each ride, many parameters of the tested vehicle and characterizing the behaviour of a driver have been recorded. The testing track consisted of the following devices:

- data acquisition station $\mu$ EEP-12 - Corrsys-Datron (Kistler) ${ }^{\circledR}$ with ARMS $^{\circledR}$ software and a control tablet, which enabled the collection, visualization and pre-processing of the results (Fig. 9);

- non-contact optoelectronic sensor S-350 Corrsys-Datron ${ }^{\star}$ which can measure the longitudinal and transverse speed of the vehicle and a vehicle drift angle (Fig. 8);

- 3 directional linear acceleration sensor of measuring range $+/-2 \mathrm{~g}$ necessary to determine the longitudinal and lateral acceleration of a car body block;

- potentiometer winding sensors for measuring displacement of control pedals: acceleration pedal, service brake and clutch, in order to determine the movement of each pedal - in order to determine the driver's reaction (Fig. 10a),

- Measurement Steering Wheel Corrsys-Datron ${ }^{\circledR}$ which allows simultaneous measurement of the angle, speed and turning torque (Fig. 10b).

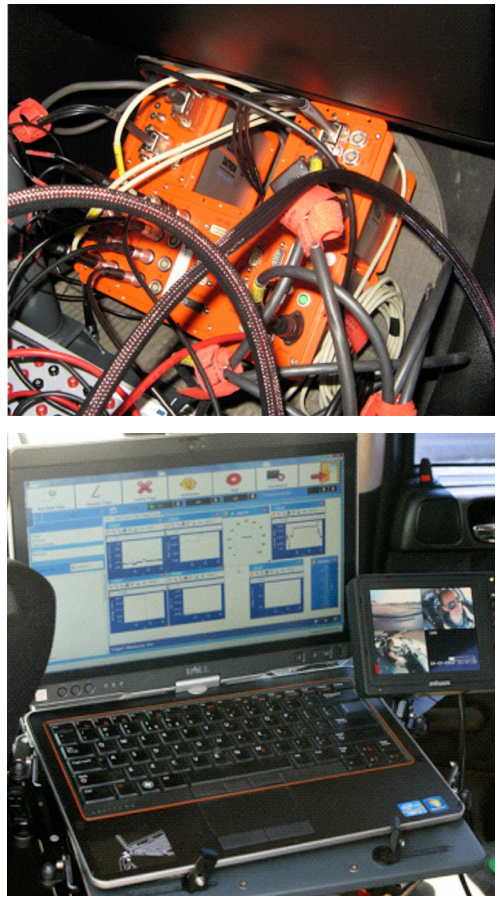

Fig. 9. Data acquisition station with the tablet and installed software

In order to enable the implementation of the assumed scenario, including independent movement of both pedestrian mock-ups and s passenger car mock-up, the authors used special systems driving independent mock-ups: the left and right pedestrian and a passenger car mock-up. To ensure the highest possible accuracy and repeatability of the measurement, a programmable radio-control motion control system of mock-ups was built. A programmable system based on PLC driver enabled fast modification test parameters, and automation of measurements (Jurecki, Ludwinek 2013).

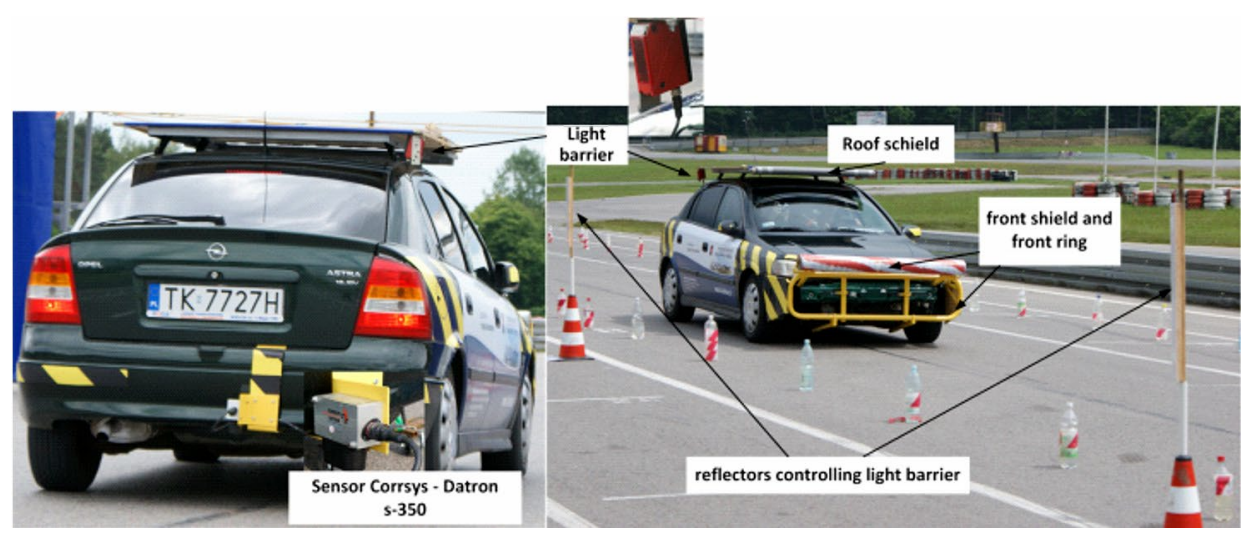

Fig. 8. Research vehicle 

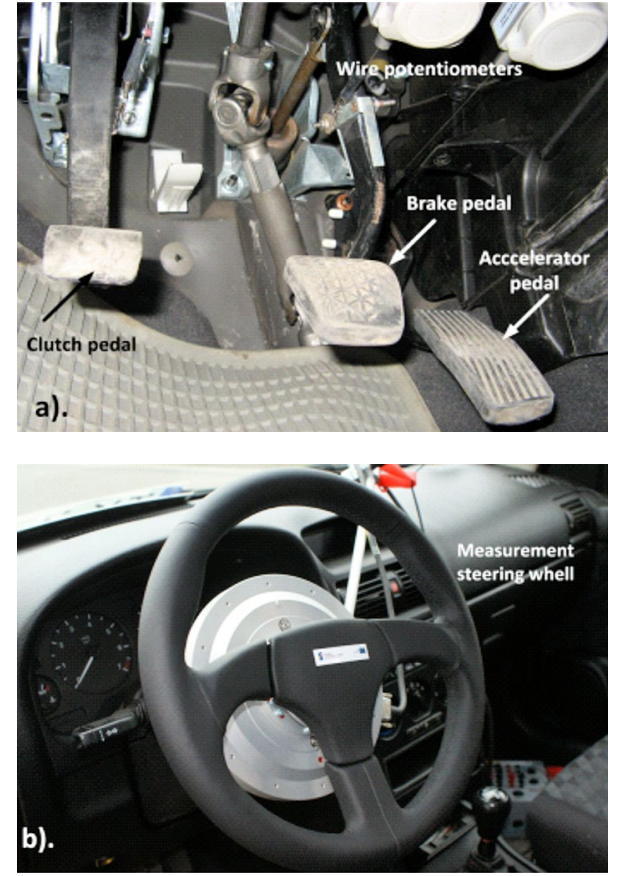

Fig. 10. View of the measuring equipment

\section{Results of Measurements}

During each of several ongoing tests a lot of measurement results are recorded. A typical set of diagrams defining the behaviour of a driver in case of accident: movement of control pedals: accelerator, brake, clutch and steering wheel angle for one of the selected tests are shown in Fig. 11.

Analysing the way of drivers reactions for an example test, it can be said that it differed significantly. In this paper the reaction time of drivers will be analysed. The following issues will be considered:

- mental reaction time, understood as the time from the moment an obstacle appears to the start of removing the foot off the accelerator - tra;

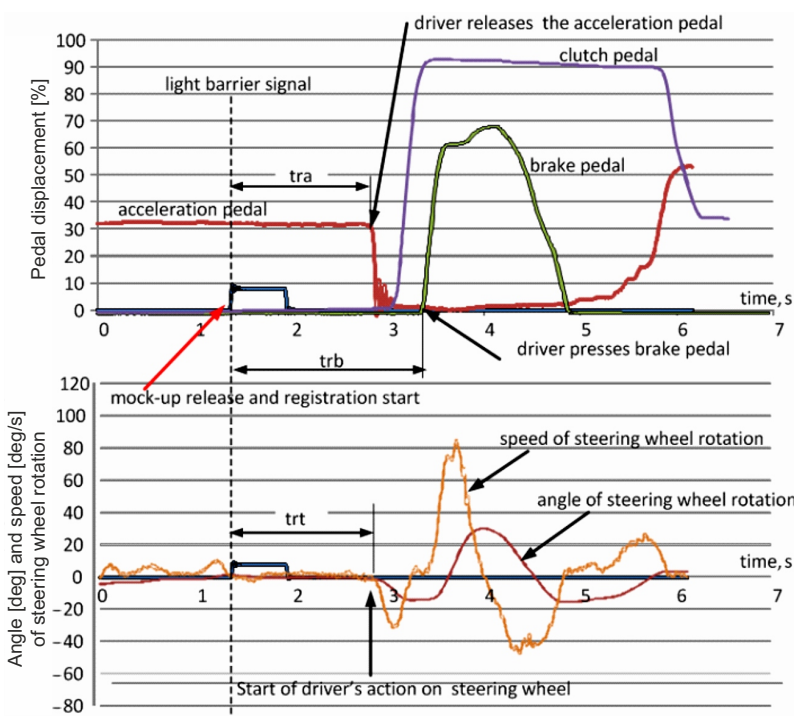

Fig. 11. Example of recorded characteristics of a single test
- psycho-motor reaction time when braking, determined as the time from the appearance of an obstacles to the appearance of force on the brake pedal - trb;

- psycho-motor reaction time during a turning, which is determined as the time from the appearance of an obstacle to the appearance of force on the steering wheel - trt.

Results of measurements of drivers' reaction time on the accelerator pedal shown as a function of TTC have been presented in Fig. 12. The diagram includes obtained, average values of reaction time on the accelerator pedal, depending on the realized situation. Analysing the obtained values, it can be said that the reaction times on the accelerator pedal are determined by TTC and grow linearly with it. The average reaction time on the accelerator pedal for each TTC values differs very little for situations A and B.

Linear regression lines designated for average reaction times on the accelerator pedal set for the two variants of the analysed scenario also confirm this fact. The regression lines for the drivers' reaction times set for the situations A and B are almost parallel, and the greater TTC value, the more these lines come together. Analysing the standard deviation of the average reaction time on the accelerator pedal, for situations A and B, it can be stated that they are in a similar range of about $0.15 \div 0.35$ s. Designated linear regression lines of standard deviations overlap. Analysing the coefficients of the equation of the regression line, it can be said that standard deviations increase slightly along with increasing TTC.

Similarly, an analysis of average reaction time set for the brake was conducted. This analysis was also performed in a function of TTC. Reaction times for brake increase with TTC in which an accident situation is considered. Analysing the diagrams of Fig. 13, it is easy to note that the reaction times of drivers on situations $\mathrm{A}$ and $B$ are almost identical. The differences of average values of reaction time for the individual values of TTC are even smaller than the reaction time to the accelerator pedal.

Designated linear regression lines of average reaction times obtained for both situations also confirm it. It is worth noting that two regression lines nearly overlap, as evidenced by coefficients of the regression line which are very close in their value.

Standard deviations demonstrating scatter measurements of reaction time of drivers to the brake pedal reach much lower values than the ones recorded for reaction times to the accelerator pedal. These variations are within the limits between $0.07 \div 0.4 \mathrm{~s}$ and slightly increase with TTC increase.

The results of the reaction time of drivers could be a surprise, as in relation to research carried out in accordance with the 'Scenario 2' (Fig. 3), when there was no obstacle to a passenger car, the results were significantly different. What can be a reason for such a change in driver's reaction? Could the emergence of additional car obstacle have such a significant impact? In the analysed scenario, the drivers' reaction time to the accelera- 


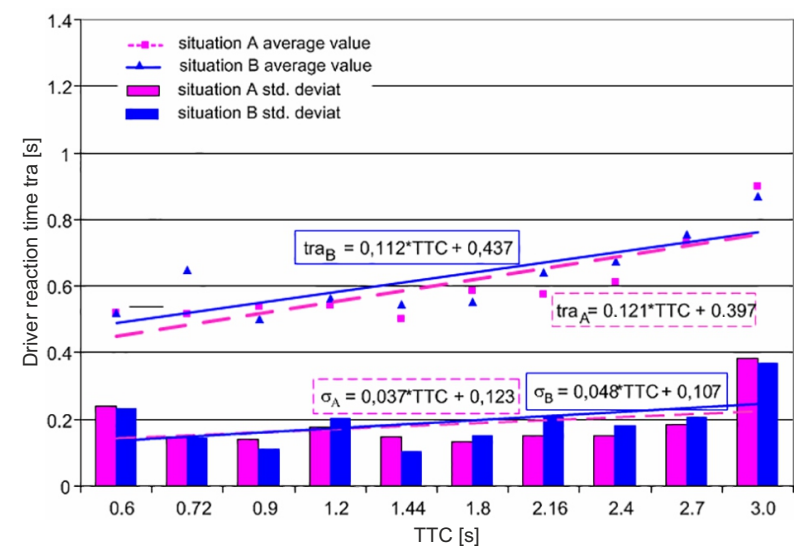

Fig. 12. The values of obtained reaction times on the accelerator pedal - tra

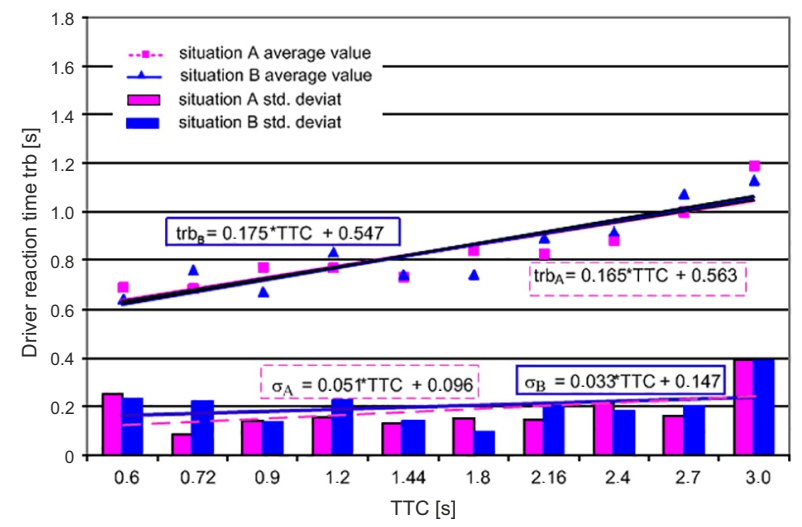

Fig. 13. The values of obtained reaction times to the brake - trb

tor is in the range $0.5 \div 0.9 \mathrm{~s}$, and in the case of the brake $0.65 \div 1.2 \mathrm{~s}$, that is much smaller than the ones recorded in the 'Scenario 4'. It can therefore be argued that even a slight modification of the scenario can significantly change the way the drivers react - on the risk, both quantitatively and qualitatively. This is a very important observation. Many publications present studies of reaction times of drivers without research methodology and the statistical analysis method. There are no basic information about the number of people tested, deviations values, etc. The use of such reaction times in accident reconstructions, without the knowledge of this very important information may be highly problematic.

Average values for reaction time for turning determined in a function of TTC, show qualitatively similar relationships, and also increase with its increase. Average reaction time for turning manoeuvre in an accident situation is not constant and it is included in a much greater range (compared to the previously examined reaction time to the accelerator and brake pedals) and equals $0.45 \div 1.4 \mathrm{~s}$. Analysing the diagram of Fig. 14, it can be seen that the reaction times of drivers to turning in situation B appear to be slightly longer.

Standard deviations providing a scatter of measurement results related to the reaction time to turning manoeuvre (measured on the steering wheel) are the

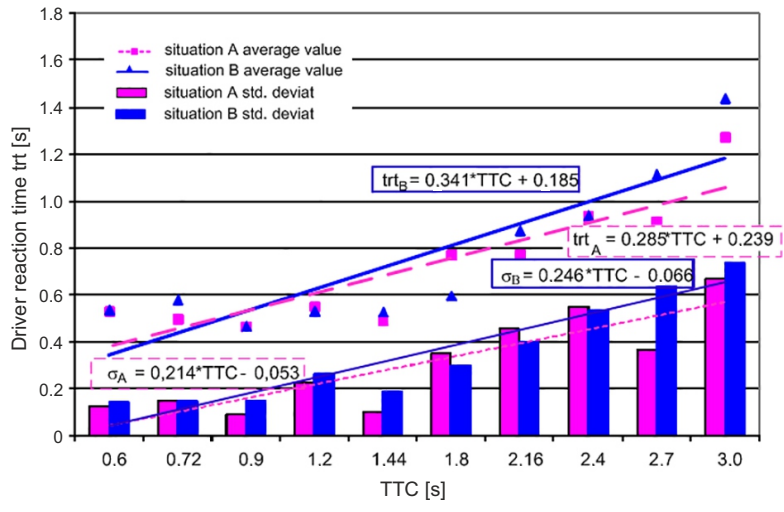

Fig. 14. The values of obtained reaction times to turning - trt

highest (in relation to the previously presented values) and are within the limits of $0.10 \div 0.77 \mathrm{~s}$. Larger deviation values, providing a greater diversity of values obtained for the time of this reaction are revealed at the higher TTC and grow along with its increase.

As the differences between average reaction times of drivers for the considered situations A and B are very small, and the standard deviations are similar, it was decided to carry out the verification of the hypothesis of equality of 2 average values.

The realized test for reaction times to the accelerator pedal at a confidence level $\alpha=0.05$ (test statistic value $|u|<1.96$ ), showed no evidence to reject this hypothesis for the reaction time values corresponding to 9 times TTC. At the confidence level of $\alpha=0.01$ (test statistic value $|u|<2.57$ ) an identical confirmation can be shown. The tests have therefore no reason to reject the null hypothesis of equality between the two average values. The values obtained for the test statistics values $|u|$ are shown in Table 2 .

A similar analysis was performed for the brake reaction time. The realized test for reaction times to the brake pedal at a confidence level of $\alpha=0.05$ showed in the majority of tests (8 tests out of 10) corresponding to different TTC, no reason to reject this hypothesis.

Table 2. Summary of test statistics values $|\mathrm{u}|$ for the accelerator reaction time

\begin{tabular}{cccc}
\hline TTC $[\mathrm{s}]$ & $u$ & $\alpha=0.05,|u|<1.96$ & $\alpha=0.01,|u|<2.57$ \\
\hline 0.60 & 0.020 & + & + \\
\hline 0.72 & -3.505 & - & - \\
\hline 0.90 & 1.157 & + & + \\
\hline 1.20 & -0.495 & + & + \\
\hline 1.44 & -1.431 & + & + \\
\hline 1.80 & 0.978 & + & + \\
\hline 2.16 & -1.561 & + & + \\
\hline 2.40 & -1.573 & + & + \\
\hline 2.70 & -0.506 & + & + \\
\hline 3.00 & 0.299 & + & +
\end{tabular}


At the confidence level of $\alpha=0.01$ the confirmation of the hypothesis can be shown for average reaction times for 9 times TTC. The values of obtained test statistics values $|u|$ are shown in Table 3 . The test performed for reaction times on the steering wheel at a confidence level $\alpha=0.05$ showed, in most tests (9 out of 10) corresponding to different TTC, no reason to reject this hypothesis. For a confidence level of $\alpha=0.01$, the hypothesis was confirmed for all tests. The values of obtained test statistics values $|u|$ are shown in Table 4 . The consequence of conducted tests and confirmation of the hypothesis of equality of average values is to treat obtained reaction times of drivers for both situations A and B in the 'Scenario 5 ' as one set.

Fig. 15 shows the driver's reaction time without distinguishing between situations A and B for data obtained in the analysed scenario.

Table 5 lists the coefficients of the equations defining the parameters of the regression line obtained reaction times to the accelerator, brake and the turn of the steering wheel.

What are the implications of the presented equations? In the case of such a complex scenario, we found that the reactions of drivers may vary significantly in relation to the seemingly similar 'Scenario 4'. An additional element of the scenario, which was the vehicle that appears from

Table 3. Summary of test statistics values $|\mathrm{u}|$ for the brake pedal reaction time

\begin{tabular}{cccc}
\hline TTC $[\mathrm{s}]$ & $u$ & $\alpha=0.05,|u|<1.96$ & $\alpha=0.01,|u|<2.57$ \\
\hline 0.60 & 0.450 & + & + \\
\hline 0.72 & -1.266 & + & + \\
\hline 0.90 & 2.553 & - & + \\
\hline 1.20 & -1.227 & + & + \\
\hline 1.44 & -0.263 & + & + \\
\hline 1.80 & 3.245 & - & - \\
\hline 2.16 & -1.482 & + & + \\
\hline 2.40 & -0.722 & + & + \\
\hline 2.70 & -1.567 & + & + \\
\hline 3.00 & 0.599 & + & + \\
\hline
\end{tabular}

Table 4. Summary of test statistics $|\mathrm{u}|$ for reaction time on the steering wheel

\begin{tabular}{cccc}
\hline TTC $[\mathrm{s}]$ & $u$ & $\alpha=0.05,|u|<1.96$ & $\alpha=0.01,|u|<2.57$ \\
\hline 0.60 & -0.136 & + & + \\
\hline 0.72 & -1.791 & + & + \\
\hline 0.90 & -0.082 & - & + \\
\hline 1.20 & 0.345 & + & + \\
\hline 1.44 & -1.027 & + & + \\
\hline 1.80 & 2.519 & - & + \\
\hline 2.16 & -0.994 & + & + \\
\hline 2.40 & -0.036 & + & + \\
\hline 2.70 & -1.616 & + & + \\
\hline 3.00 & -0.919 & + & + \\
\hline
\end{tabular}

a transverse road, caused significant changes of obtained reaction times. This confirms the thesis that the reaction time values should be determined only for similar (specific) situations.

In the case of the analysed scenario, it occurred that the reaction time values to situations $A$ and $B$ are very similar. Hence, averaging these values can be considered reasonable. How can this be explained? The main reason is the occurrence of two obstacles at the same time. In the analysed scenario, the extent to which the situation was complicated became less important (in terms of reaction time of drivers) than the complexity of the scenario itself. The table below shows in bold line regression equation coefficients shown in Fig. 15, for situations $A$ and $B$ (without distinguishing between situations $A$ and $B$ ) reaction time values.

Having the data concerning measures taken by drivers as for manoeuvres in each test, their usage frequency by a driver was determined. The frequency of execution of a specific manoeuvre was calculated as the ratio of tests in which there was driver's reaction to the total number of realized tests. Analysing the accelerator pedal reaction, the frequency of taking such a reaction was determined (Fig. 16).

It is very high and in some test options, it reaches $100 \%$. It is worth noting that the frequency of the accelerator reaction time for minimum values of TTC equals values from $75 \div 92 \%$ and then it is stabilized at a very high level of $95 \div 100 \%$. The frequency of the driver's reaction to the accelerator pedal in this scenario is higher

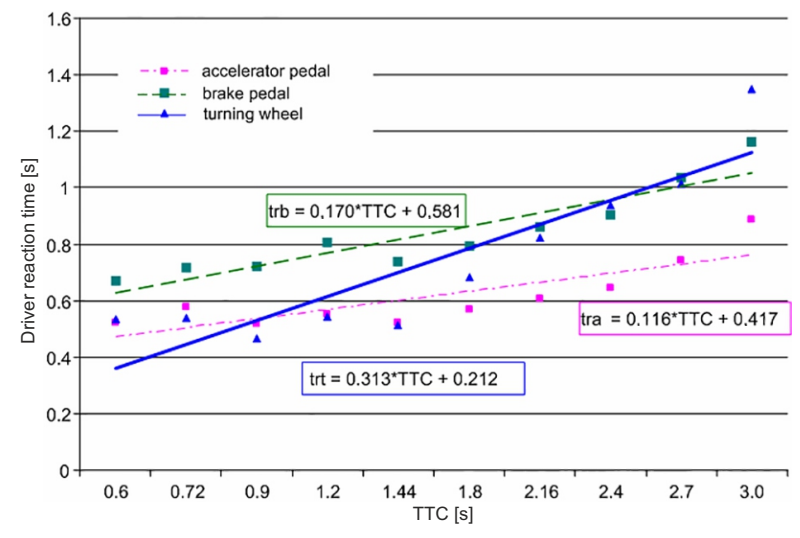

Fig. 15. Average reaction times for 'Scenario 5', without distinguishing between situations $\mathrm{A}$ and $\mathrm{B}$

Table 5. Summary of the linear regression equation coefficients of drivers' reaction time

\begin{tabular}{l|ccc|cc|cc}
\hline \multicolumn{7}{c|}{ Equation $t r \ldots=a \cdot T T C+b$} \\
\hline \multicolumn{1}{c|}{ Situation } & \multicolumn{2}{|c|}{$\mathrm{A}$} & \multicolumn{2}{c|}{$\mathrm{B}$} & \multicolumn{2}{c}{ A and B } \\
\hline Coefficients & $a$ & $b$ & $a$ & $b$ & $\boldsymbol{a}$ & $\boldsymbol{b}$ \\
\hline $\begin{array}{l}\text { Accelerator } \\
\text { pedal - tra }\end{array}$ & 0.121 & 0.397 & 0.112 & 0.437 & $\mathbf{0 . 1 1 6}$ & $\mathbf{0 . 4 1 7}$ \\
\hline $\begin{array}{l}\text { Service brake } \\
\text { pedal - trb }\end{array}$ & 0.165 & 0,563 & 0.175 & 0.547 & $\mathbf{0 . 1 7 0}$ & $\mathbf{0 . 5 8 1}$ \\
\hline $\begin{array}{l}\text { Steering wheel } \\
\text { turning) - trt }\end{array}$ & 0.285 & 0.239 & 0.341 & 0.185 & $\mathbf{0 . 3 1 3}$ & $\mathbf{0 . 2 1 2}$ \\
\hline
\end{tabular}


than the ones determined for 'Scenario 4'. Therefore, it should be noted that this reaction, especially at higher TTC, can only initiate the next reaction of a driver that is braking associated with pressing the brake pedal.

For this reason, an assessment of the frequency of the driver's reaction to the pedal brake was carried out. Analysing driver's reaction, the frequency of taking a braking manoeuvre by a driver was determined (Fig. 17). It is worth to mention that the frequency of taking reaction to the brake pedal for minimum TTC values reaches from the value from 40 to $60 \%$ and is much larger than the designated for 'Scenario 4'.

For small values of TTC, the frequency is about $40 \div 50 \%$, and above TTC value about $1.44 \div 2.00 \mathrm{~s}$ it is stabilized at a relatively high level of $85 \div 100 \%$. The sig-

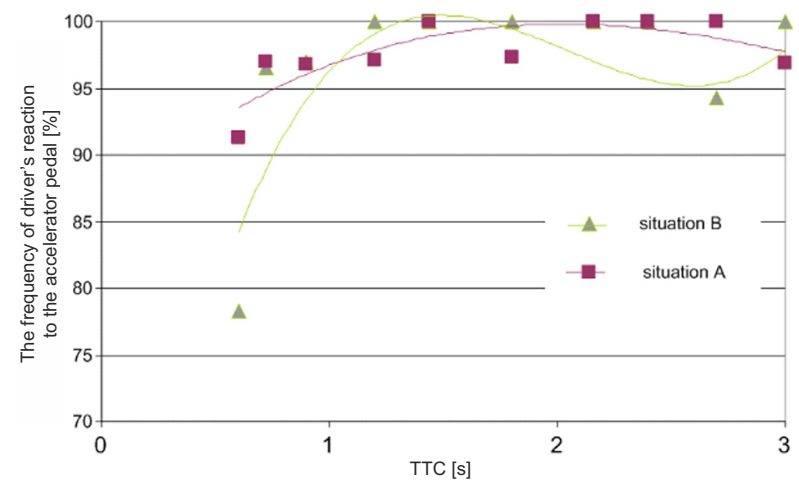

Fig. 16. The values of the frequency of accelerator pedal reaction time

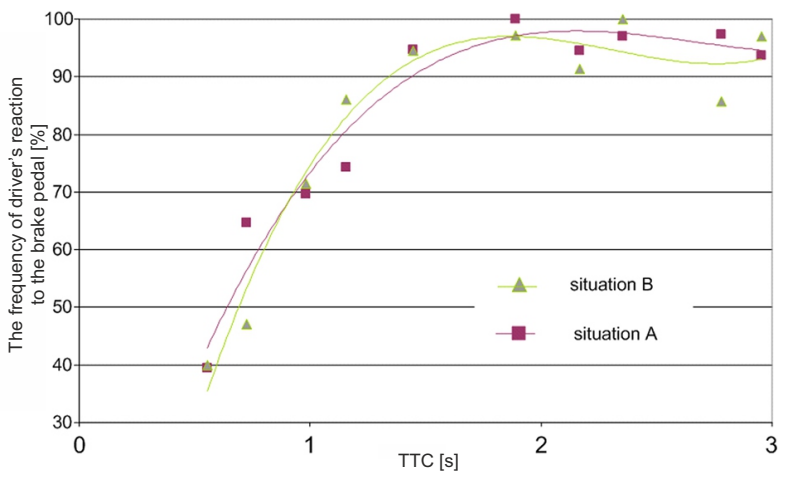

Fig. 17. The values of the frequency of brake pedal reaction

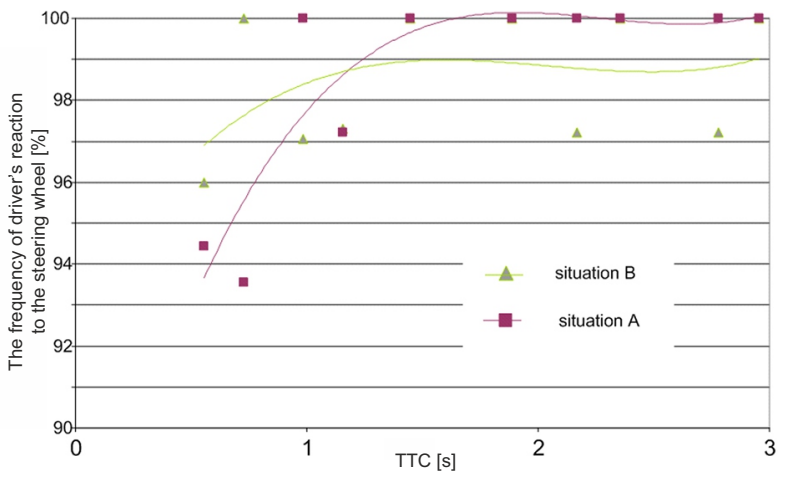

Fig. 18. The values of the frequency of the driver's reaction to a steering wheel nificant difference between the reactions of the driver in situations A and B cannot be observed.

Analysing the diagrams in Figs 16 and 17, one might ask a questions why such a difference between the reactions consisting in releasing the accelerator pedal and pressing the brake pedal appears. Drivers as a result of an accident emergency situation instinctively react releasing the accelerator pedal and therefore start a braking manoeuvre. The problem is that at the minimum TTC, it is, in most cases, very often too late to use service brake and drivers do not press the brake pedal.

The assessment of the frequency of the driver's reaction to a steering wheel is shown in Fig. 18. In contrast to previously presented diagrams (Figs 16 and 17), it is easy to see that the frequency to take a steering reaction is relatively the greatest. Only for the lowest tests of TTC 0.60 to 0.72 s, it was slightly over $93 \%$.

Above TTC value of $0.9 \mathrm{~s}$, the frequency value of execution of a steering manoeuvre is very high and equals $97 \div 100 \%$. An apparent difference in the frequency of taking (not fully complete) this manoeuvre for situation $\mathrm{A}$ and $\mathrm{B}$ cannot be shown. The frequency of steering wheel reaction with the start of avoidance manoeuvre in the analysed scenario is very high. In previous studies by the authors (Jurecki, Stańczyk 2009; Stańczyk et al. 2010, 2011, 2012) especially for very small TTC values, drivers decided to take bypass manoeuvres to avoid an obstacle much more rarely.

\section{Conclusions}

The authors established a lot of goals while pursuing the study of drivers in simulated accident situations. One of them was to determine the reaction time of drivers.

Drivers' reaction times have been shown as TTC (Time To Collision) function. These times have an increasing trend with increasing TTC, which confirms the validity of the earlier studies of the authors.

Reaction times set for the two considered situations in the scenario can be considered identically. Performed statistical analysis to test the hypothesis of the equality of two average values revealed no grounds for its rejection.

Despite big similarity of the two scenarios - 'Scenario 4' and 'Scenario 5', it occurred that extending the scenario of an additional obstacle (car entering into the area of the road from the right-hand side), ended in dramatical change in obtained results. This situation was a big surprise for the authors. Obtained values of reaction time in 'Scenario 5' were shorter, but no difference was observed for the case of situation A and B that differed in side, from where the pedestrian model enters. It can therefore be argued that the realization of the research into drivers' behaviour should be continued for a wide range of possible scenarios. Another very important finding is also that results of reaction times cannot be used interchangeably even for seemingly similar scenarios. It is therefore difficult to determine how even a slight modification of the scenario (in this case 'Scenario 5') may affect obtained results. 
Linear regression and turn index equations of drivers' reaction times were also determined. In addition to the reaction, the analysis also covered standard deviation values of the reaction time values.

Analysing the frequency of taking defensive manoeuvres by drivers, it can be said that most manoeuvres for situations A and B are similar. In the case of the reaction to the accelerator pedal and steering wheel it is very high. The frequency of using a service brake increases from $40 \%$ for the lowest values of TTC to about $95 \div 100 \%$ of the TTC which amounts to $1.8 \mathrm{~s}$. After this time, the frequency decreases slightly and it ranges $85 \div 95 \%$. Compared to previous studies of the authors, the difference on the frequency of manoeuvres avoidance should be observed. In the analysed scenario, such manoeuvres were carried out more frequently, although it is worth noting that the initiation of such a manoeuvre is not equivalent to its correct (full) end.

\section{Acknowledgements}

The Project N N509 549040 was funded by the National Science Centre (Poland).

\section{References}

Alm, H.; Nilsson, L. 1995. The effects of a mobile telephone task on driver behaviour in a car following situation, Accident Analysis \& Prevention 27(5): 707-715. http://dx.doi.org/10.1016/0001-4575(95)00026-V

Burckhardt, M.; Burg, H.; Gnadler, R.; Näumann, E.; Schiemann, G. 1981. Die Brems-Reaktionsdauer von Pkw-Fahrern, Verkehrsunfall 19(12): 224-236 (in German).

Baulk, S. D.; Reyner, L. A.; Home J. A. 2001. Driver sleepiness - evaluation of reaction time measurement as a secondary task, Sleep 24(6): 695-698.

Consiglio, W.; Driscoll, P.; Witte, M.; Berg, W. P. 2003. Effect of cellular telephone conversations and other potential interference on reaction time in a braking response, Accident Analysis \& Prevention 35(4): 495-500.

http://dx.doi.org/10.1016/S0001-4575(02)00027-1

Connor, J.; Norton, R.; Ameratunga, S.; Robinson, E.; Civil, I.; Dunn, R.; Bailey, J.; Jackson, R. 2002. Driver sleepiness and risk of serious injury to car occupants: population based case control study, BMJ 324: 1125-1128.

http://dx.doi.org/10.1136/bmj.324.7346.1125

Dettinger, J. 2008. Reaktionsdauer bei Notbremsungen - Entwicklung und Status quo des Erkenntnisstandes - Teil 1. Verkehrsunfall und Fahrzeugtechnik 46(6): 180-187 (in German).

Fröming, R. 2008. Assessment of Integrated Pedestrian Protection Systems. Dissertation. Technische Universität Berlin. 113 S. (in German).

Ganz, S. B.; Levin, A. Z.; Peterson, M. G.; Ranawat, C. S. 2003. Improvement in driving reaction time after total hip arthroplasty, Clinical Orthopaedics and Related Research 413: 192200. http://dx.doi.org/10.1097/01.blo.0000072468.32680.ff

Green, M. 2000. "How long does it take to stop?" Methodological analysis of driver perception-brake times, Transportation Human Factors 2(3): 195-216. http://dx.doi.org/10.1207/STHF0203_1

Guzek, M.; Jurecki, R.; Lozia, Z.; Stańczyk, T. L. 2006. Comparative analyses of driver behaviour on the track and in virtual environment, in Proceedings of the Driving Simulation Conference DSC 2006 - Europe, 4-6 October 2006, Paris, France, 221-232.

Hillenbrand, J. 2007. Fahrerassistenz zur Kollisionsvermeidung. Dissertation. Karlsruher Institut für Technologie. $218 \mathrm{~S}$. Available from Internet: http://digbib.ubka.uni-karlsruhe. de/volltexte/1000007728 (in German).

Hindmarch, I. 2004. Psychomotor function and psychoactive drugs, British Journal of Clinical Pharmacology 58(7): S720S740. http://dx.doi.org/10.1111/j.1365-2125.2004.02279.x

Hugemann, W. 2002. Driver reaction times in road traffic, in Proceedings of the Annual Meeting of the European Association for Accident Research and Analysis (EVU 2002), 6-7 September 2002, Portorož, Slovenija. 12 p.

Jurecki, R.; Ludwinek, K. 2013. The control system of mockups in the study drivers' behavior in case of emergency situations, Przeglad Elektrotechniczny 89(4): 71-79.

Jurecki, R.; Stańczyk, T. L. 2011a. Driver Model for the analysis of pre-accident situations- similarities and differences of results on a track and in a simulator, The Archives of Automotive Engineering / Archiwum Motoryzacji 51(1): 31-53.

Jurecki, R. S.; Stańczyk, T. L. 2011b. The test methods and the reaction time of drivers, Eksploatacja i Niezawodność Maintenance and Reliability (3): 84-91.

Jurecki, R.; Stańczyk, T. L. 2009. Driver model for the analysis of pre-accident situations, Vehicle System Dynamics 47(5): 589-612. http://dx.doi.org/10.1080/00423110802276028

Keall, M. D.; Frith, W. J.; Patterson T. L. 2004. The influence of alcohol, age and number of passengers on the night-time risk of driver fatal injury in New Zealand, Accident Analysis \& Prevention 36(1): 49-61. http://dx.doi.org/10.1016/S0001-4575(02)00114-8

Krause, R.; De Vries, N.; Friebel, W.-C. 2007. Mensch und Bremse in Notbremssituationen mit Pkw - neue Erkenntnisse zu Prozesszeiten beim Bremsen - Teil 1, Verkehrsunfall und Fahrzeugtechnik 45(6): 164-171 (in German).

Lee, J. D.; McGehee, D. V.; Brown, T. L.; Reyes, M. L. 2002. Collision warning timing, driver distraction, and driver response to imminent rear-end collisions in a high-fidelity driving simulator, Human Factors 44(2): 314-334. http://dx.doi.org/10.1518/0018720024497844

Magister, T.; Krulec, R.; Batista, M.; Bogdanović, L. 2005. The driver reaction time measurement experiences, in Proceedings of the 7th Conference and Exhibition Innovative Automotive Technology IAT'05, 21-22 April 2005, Bled, Slovenia, 751-761.

McGehee, D. V.; Mazzae, E. N.; Baldwin, S. G. H. 2000. Driver reaction time in crash avoidance research: validation of a driving simulator study on a test track, in Proceedings of the Proceedings of the IEA 2000/HFES 2000 Congress, San Diego, California, USA, Vol. 3: 320-323.

Madeley, P.; Hulley, J. L.; Wildgust, H.; Mindham, R. H. 1990. Parkinson's disease and driving ability, Journal of Neurology, Neurosurgery \& Psychiatry 53(7): 580-582. http://dx.doi.org/10.1136/jnnp.53.7.580

Nishida, Y. 1999. Driving characteristics of the elderly: risk compensation of the elderly driver from the viewpoint of reaction behavior, JSAE Review 20(3): 375-380. http://dx.doi.org/10.1016/S0389-4304(99)00030-2

Ogden, E. J. D.; Moskowitz, H. 2004. Effects of alcohol and other drugs on driver performance, Traffic Injury Prevention 5(3): 185-198. http://dx.doi.org/10.1080/15389580490465201 
Oxley, J.; Lenné, M.; Corben, B. 2006. The effect of alcohol impairment on road-crossing behaviour, Transportation Research Part F: Traffic Psychology and Behaviour 9(4): 258-268. http://dx.doi.org/10.1016/j.trf.2006.01.004

Philip, P.; Sagaspe, P.; Moore, N.; Taillard, J.; Charles, A.; Guilleminault, C.; Bioulac, B. 2005. Fatigue, sleep restriction and driving performance, Accident Analysis \& Prevention 37(3): 473-478. http://dx.doi.org/10.1016/j.aap.2004.07.007

Spalding, T. J. W.; Kiss, J.; Kyberd, P.; Turner-Smith, A.; Simpson, A. H. R. W. 1994. Driver reaction times after total knee replacement, The Bone \& Joint Journal [The Journal of Bone \& Joint Surgery] 76-B(5): 754-756.

Stańczyk, T. L.; Jurecki, R.; Jaśkiewicz, M.; Walczak, S.; Janczur, R. 2011. Researches on the reaction of a pedestrian stepping into the road from the right side from behind and an obstacle realized on the track, Journal of KONES: Powertrain and Transport 18(1): 615-622.

Stańczyk, T. L.; Jurecki, R. S.; Zuska, A.; Walczak, S.; Maniowski, M. 2012. On the track researches of driver's reaction time to the big lorry entering the crossroad from the right side with limited visibility, in Problems of Maintenance of Sustainable Technological Systems, Vol. IV: Automotive Engineering and Vehicle Safety Engineering, Kielce, 140-151.

Stańczyk, T. L.; Lozia, Z.; Pieniążek, W.; Jurecki, R. S. 2010. Research studies on drivers' reactions for incoming vehicle from right-hand side, in Proceedings of the 19th Annual Congress EVU 2010, 14-16 October 2010, Prague, Czech Republic, 41-53.

Törnros, J. 1995. Effect of driving speed on reaction time during motorway driving, Accident Analysis \& Prevention 27(4): 435-442. http://dx.doi.org/10.1016/0001-4575(94)00084-Y

Zaranka, J.; Guzek, M.; Pečeliūnas, R. 2011. Experimental research on influence of alcohol on drivers psychophysiological quality, in TRANSBALTICA 2011: Proceedings of the 7th International Scientific Conference, 5-6 May 2011, Vilnius, Lithuania, 155-158.

Zöller, H.; Hugemann, W. 1998. Zur Problematik der Bremsreaktionszeit im Straßenverkehr. 22 p. Available from Internet: http://www.unfallrekonstruktion.de/pdf/bdp_1998_ german.pdf (in German). 